\title{
Does acute hyperglycaemia influence heat pain thresholds?
}

\author{
A W CHAN, I A MacFARLANE, D R BOWSHER, * J C D WELlS* \\ From the Diabetic Clinic and Pain Relief Foundation, * Walton Hospital, Liverpool, UK
}

SUMMARY The influence of acute hyperglycaemia on pain sensation was assessed in eight young adult non-diabetic subjects. Acute hyperglycaemia was induced with IV glucose in a double blind fashion, with IV saline as a control. Pain thresholds were assessed by a painful heat stimulus delivered by a Marstock thermode on the thenar eminence. Heat pain thresholds did not significantly alter during either acute hyperglycaemia or the control saline infusion. Previous work demonstrating a lowering of electrical pain thresholds by hyperglycaemia has therefore not been confirmed using a natural painful stimulus.

Experimental work in animals has shown that hyperglycaemia can reduce the antinociceptive potency of morphine. ${ }^{1}$ Morley et $a l^{2}$ have shown that acute hyperglycaemia lowered thresholds to painful electrical stimulation in normal human subjects. These findings are compatible with the hypothesis that hyperglycaemia, or rapid fluxes in blood glucose levels, increase pain sensitivity. They also showed that diabetic subjects had a lower pain tolerance compared with non-diabetic controls. Morley and colleagues conclude from their studies that glucose may modulate opioid receptors in man. A recent editorial called for further work on the association between hyperglycaemia, pain perception, and possible glucose modulation of opioid receptors. ${ }^{3}$ Electrical stimuli of sufficient intensity to activate nociceptive fibres will perforce generate impulses in every other kind of nerve fibre. Therefore, we favour the use of a noxious heat stimulus, which selectively activates small $\mathrm{A} \delta$ and $\mathrm{C}$ fibres. ${ }^{45} \mathrm{We}$ assessed the influence of hyperglycaemia on pain thresholds using a noxious heat stimulus, delivered by a Marstock thermode. ${ }^{6}$

\section{Subjects}

Eight healthy, non-diabetic subjects (4 male), mean age 25 years (range 18-38), were studied. All had normal fasting blood glucose ( $<6 \mathrm{mmol} / \mathrm{l})$ and glycosylated haemoglobin values of less than $7 \%$ (laboratory reference: $5-8 \%$ ), and were taking no medications.

Address for reprint requests: Dr A W Chan, Diabetic Clinic, Walton Hospital, Liverpool L9 IAE, UK.

Received 9 October 1987 and in revised form 3 December 1987. Accepted 5 January 1988

\section{Methods}

The subjects were studied after an overnight fast and all experiments were conducted in a quiet room with an ambient temperature of $19^{\circ} \mathrm{C}$. Two intravenous cannulae were inserted, one in each antecubital fossa. Each subject was tested twice in a randomised, double blind, crossover study to receive either an intravenous bolus of 50 gram glucose in $100 \mathrm{ml}$ or an equivalent volume of normal saline. The alternative injection was given a week later. All injections were made over a period of 2 minutes. Venous blood for glucose estimation was taken at 15 minutes before injection (fasting), and $0,5,10,20,30,40,50,60$ minutes afterwards. Heat pain and cold thresholds (HPT and CT) were obtained with a Marstock thermode attached to the thenar eminence of the non-dominant hand and held in place by a small weight. ${ }^{6} \mathrm{~A}$ constant current of $2 \mathrm{~A}$ was delivered to the stimulating plate and the test subject indicated the perceived thermal threshold by pressing a switch which reversed the direction of the current and therefore of the temperature change. The thermode was thermally buffered by circulating water at $35^{\circ} \mathrm{C}$. The temperature of the stimulating plate was measured by a thermocouple and displayed on a chart recorder. The HPT and CT were measured over 5 minutes and mean values calculated at the following times: 15, 5 minutes before injection (two fasting values), and $0,10,20$, 30, 40, 50, 60 minutes afterwards.

The study design was approved by the local ethical committee.

\section{Statistics}

Blood glucose, HPT, and CT for the eight subjects are given as mean, SD. The HPT and CT after IV saline were compared with those following IV glucose using Student's paired $t$ tests. 


\section{Results}

The mean fasting blood sugar (SD) on the two test days were similar: $4.8 \mathrm{mmol} / 1(0.4)$ for IV saline, and $5.0 \mathrm{mmol} / 1(0.4)$ for IV glucose. Fifty gram of IV glucose produced a prompt and marked rise in blood sugars (fig 1), reaching a maximum of $21.1 \mathrm{mmol} / 1$ (6.7) at 5 minutes. In six subjects some discomfort in the arm was reported during the time of the injection. When the study was completed, it was realised that the discomfort occurred during the glucose injection in all

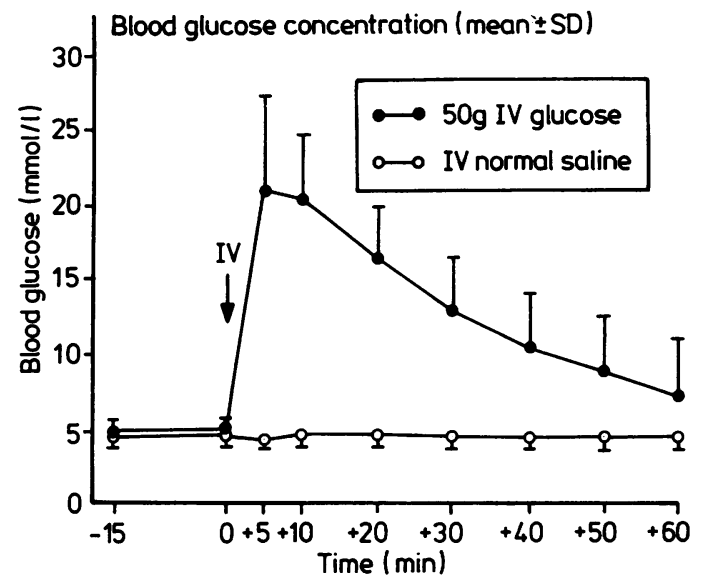

Fig 1 The mean blood glucose concentration ( $S D)$ for the eight subjects after IV infusion of either $50 \mathrm{~g}$ glucose or an equivalent volume of normal saline given at time 0 minutes.

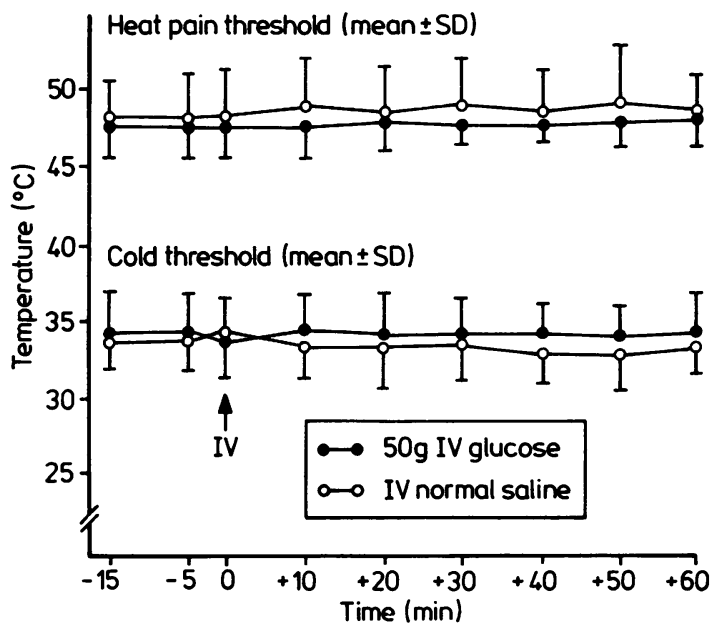

Fig 2 The mean heat pain threshold (SD) and cold threshold (SD) for the eight subjects. IV 50 grammes glucose or an equivalent volume of normal saline is given at time 0 minutes. Heat pain threshold and cold threshold did not significantly alter during either acute hyperglycaemia or the control saline infusion. six subjects. Mean HPT values were similar before IV saline and glucose $\left(47.9^{\circ} \mathrm{C}, 2.6\right.$ versus $47.7^{\circ} \mathrm{C}, 2 \cdot 0, \mathrm{p}>$ $0 \cdot 5$, NS). Mean CT values before IV saline and glucose were not significantly different $\left(34.5^{\circ} \mathrm{C}, 2 \cdot 3\right.$ versus $34.6^{\circ} \mathrm{C}, 2 \cdot 8, \mathrm{p}>0.5$ ). There was no significant change in HPT and CT after either intravenous glucose or normal saline (fig 2). One subject showed a transient rise and fall in HPT and CT, which coincided with the 2 minute IV glucose injection and the onset of discomfort at the infusion site.

\section{Discussion}

We conclude from our study that acute hyperglycaemia in healthy subjects does not affect the perception of thermally induced pain. The effect of hyperglycaemia on the perception of other natural pain stimuli cannot however be inferred from our heat pain data. Rapid IV glucose injection given in a forearm vein may cause sufficient discomfort to affect the perception of thermally induced pain administered at another site, as demonstrated in one of our subjects. Our results in healthy individuals may not be applicable to diabetic patients, who have rapid fluxes in blood glucose superimposed on a background of chronic hyperglycaemia. In diabetic patients tight glycaemic control has been shown to alleviate chronic neuropathic pain, ${ }^{7}$ but the effect of glycaemic status on the severity of other kinds of chronic pain is as yet unexplored.

Our findings are at variance with those of Morley et $a l^{2}$ and may be due to important differences in methodology. We used heat pain and thermal sensation which are generally accepted to be conveyed by small myelinated (A $\delta$ ) and smaller unmyelinated (C) fibres. ${ }^{45}$ These fibres may be selectively involved in painful diabetic neuropathy..$^{8-10}$ Morley used an electrical stimulus which is highly unnatural, and is subject to variability of impedance and of route of current flow. ${ }^{5}$ The identity of the receptor(s) stimulated and the type(s) of afferent fibre transmitting the stimulus are unspecified with electrical methods. For these and other reasons, electrical stimulation of the skin as a means of inducing pain (or any other sensation) is now regarded with considerable disfavour by human physiologists.

Two other important criticisms can be made of Morley et al's paper. First, it was single blind in design. Secondly, the time of occurrence of (a) the maximal fall in electrical pain threshold and (b) blood glucose peaks and troughs after IV glucose is not given. Therefore, the relationship between electrical pain threshold and prevailing blood glucose level is not clear. Any fall in electrical pain threshold observed by Morley et al may have been precipitated by the discomfort of rapid glucose injection. The 
recent literature has extensively quoted the work of Morley et al with unquestioned acceptance of their observations and assumptions. ${ }^{311-13}$ However, we feel that it is unwise, in view of their methodological problems and our demonstration of failure of acute hyperglycaemia to influence heat pain thresholds, to assert that hyperglycaemia affects pain perception threshold. Indeed, we believe that we have adduced convincing evidence that it does not.

The assistance of the Pharmacy Department Walton Hospital, and the participation of the voluneteers are gratefully acknowledged. We thank Novo Laboratories Ltd for generous financial support.

\section{References}

1 Simon GS, Dewey WL. Narcotics and diabetes I. The effects of streptotocin-induced diabetes on the antinociceptive potency of morphine. J Pharmacol Exp Ther 1981;218:318-23.

2 Morley GK, Mooradian AD, Levine AS, Morley JE. Mechanism of pain in diabetic peripheral neuropathy. Effect of glucose on pain perception in humans. Am J Med 1984;77:79-82.

3 Editorial. Pain Perception In Diabetic Neuropathy. Lancet 1985:83-4.

4 Hammond DL, Yaksh TL. Peripheral and central pathways in pain. In: Williams NE, Wilson $\mathrm{H}$, eds. Pain and Management. Oxford: Pergamon Press, 1983:33-49.
5 Dyck PJ, Karnes J, O'Brien PC, Zimmermann IR. Quantitation of cutaneous sensation in man. In: Dyck PJ, Thomas PK, Lambert EW, Bunge R, eds. Peripheral Neuropathy. Philadelphia: Saunders, 1984;1:1103-38.

6 Furhstorfer H, Lindblom U, Schmidt WG. Method for quantitative estimation of thermal thresholds in patients. J Neurol Neurosurg Psychiatry 1976;39: 1071-5.

7 Boulton AJM, Drury J, Clarke B, Ward JD. Continuous subcutaneous insulin infusion in the management of painful diabetic neuropathy. Diabetes Care 1982;5: 386-90.

8 Brown MJ, Martin JR, Asbury AK. Painful diabetic neuropathy. A morphometric study. Arch Neurol 1976;33:164-71

9 Guy RJC, Clark CA, Malcolm PN, Watkins PJ. Evaluation of thermal and vibration sensation in diabetic neuropathy. Diabetologia 1985;28:131-7.

10 Heimans JJ, Bertelsmann FW, Van Rooy JCGM. Large and small nerve fibre function in painful diabetic neuropathy. J Neurol Sci 1986;74:1-9.

11 Boulton AJM, Ward JD. Painful diabetic neuropathies. Clin Endocrinol Metabol 1986;15(4):917-31.

12 Thomas PK, Scadding JW. Treatment of pain in diabetic neuropathy. In: Dyck PJ, Thomas PK, Asbury AK, Winegrad AI, Porte D, eds. Diabetic neuropathy. Philadelphia: Saunders, 1987:216-22.

13 Wuarin-Biermann L, Zahnd GR, Kaufman F, Burcklen L, Adler J. Hyperalgesia in spontaneous and experimental animal models of diabetic neuropathy. Diabetologia 1987;30:653-8. 